\title{
ART AND THE TEACHING OF ENGLISH AS A FOREIGN LANGUAGE TEFL: A CONTENT AND LANGUAGE INTEGRATED LEARNING CLIL MULTI- Cultural APproach
}

\author{
BY \\ Haggag Mohamed Haggag (PhD) \\ SOUTH VALLEY UNIVERSITY \\ Hurghada Faculty Of Education
}

DOI : 10.12816/0052742

مجلة الدراسات التريوية والانسانية ـ كلية التربية ـ جامعة دمنهور

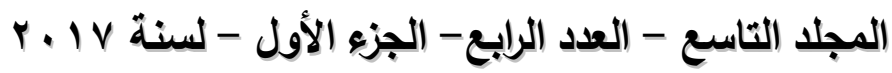




\title{
ART AND THE TEACHING OF ENGLiSH AS A FOREIGN \\ LANGUAGE TEFL: A CONTENT AND LANGUAGE INTEGRATED LEARNING CLIL MULTI-CULTURAL APPROACH Haggag Mohamed Haggag (PhD)
}

DOI : $10.12816 / 0052742$

\begin{abstract}
English is the world's first language as Art is an international language as well. This paper discusses the theory and a possible practice of using art in the teaching of English as a foreign language from the Multicultural Content and Language Integrated Learning (CLIL) perspective. A discussion of the various ways of integrating Art in EFL course design, teaching and assessment is presented in the light of CLIL approach. The research discusses using CLIL in the teaching of English as a foreign language. Tools and materials of the research included: (1) Content analysis questionnaire (2) Needs assessment questionnaire (3) CLIL art-oriented questionnaire (4) CLIL-based module (5) CLIL-based test (6) Satisfaction scale. In a quasiexperimental one-group design (N.25), an Art-oriented CLIL module was administered over the participants following a pre and post testing procedure. The research tested both participants' English language achievement as well as their satisfaction with the art-oriented courses. Results of administering the instruments and the module showed a development in the participants' language achievement (mainly grammar, vocabulary, reading and writing) as well as a positive development in their satisfaction with the module. Recommendations of the research calls for Art integration in language courses and designing CLIL based multicultural courses for better language practice.
\end{abstract}

Key words:

TEFL - Art Education-CLIL-Multiculturalism 


\section{Introduction:}

Art and language disciplines intervene in their goals, procedures and assessment methods since they complement and foster each other. For instance, Vazquez $(2015$, p.1) describes the match between art and language as an interrelated relationship asserting that "language and art can complement and assist each other. When a concept is not clear in its written form, the visual form can assist the learner to comprehend, and likewise when the visual form is confusing and unclear, the written form can facilitate understanding". The relation between art and language is obvious and consequently foreign language teaching uses art in its approaches and theories.

The relation between different Arts (the present research refers to arts to mean music, visual arts, drama, dance and literature/creative writing, etc), teaching and learning is described by Hashemi \& Farokhi (2012, p.26) as a foster to comprehension and communication:

Art has always been an effective tool for teaching and learning among various classes of people. When combined with reading, writing, speaking and listening, Art can open doors for high levels of analysis and also challenge students to explore themselves and their surroundings and thus find avenues for sophisticated comprehension and communication.

Emerging arts in language classes engages the students in a doing act during activities which is the core of active learning practices. Arts foster students' autonomy and help them take control of their learning. In this view, The New York State Education Department (2010, p.3) sates in its document about the use of Art as a tool for language teachers that "placing Art within the context of the lives of ELLs and enabling them to express their ideas visually as well as by speaking and writing. Art can help teachers to do the following:

- Build on prior knowledge.

- Scaffold instruction.

- Create a bridge between written and spoken language.

- Make learning relevant and meaningful.

- Help students develop their self-esteem.

- Foster creativity.

- Develop an appreciation of the past.

-Highlight similarities and differences.

- Foster higher order thinking skills.

-Promote high levels of analysis, reasoning, and questioning.

-Support creative thinking. 
-Model problem solving.

-Emphasize interpreting and communication of ideas.

-Enhance students' ways of observing, responding to, and representing the world.

Therefore, Art can be a useful tool as well as content for English language courses and materials due to the advancements it adds to the knowledge, skills and attitudes of the learners.

For the various impacts of arts in teaching and learning in general and particularly in teaching and learning English, various approaches have been developed and one of the key approaches to teaching language through Art is Multiculturalism. There are key approaches that attempted to integrate specific disciplines (as history, science, geography ...etc.) with language development. These approaches are mainly English for Specific Purposes ESP and Content Based Instruction CBI. These approaches initiated the integration between content and language and paved the way to the emergence of Content and Language Integrated Learning CLIL approach.

Content and Language Integrated Learning CLIL approach emerged with the aim of both language and content development in Europe. This value of language and content integration was highlighted by Wolf (2009, p. 560) stating that " The experience shows that both linguistic and content subject competence can be promoted within this integrated concept more effectively than when content and language are taught in isolation". Using CLIL in language development was highlighted in many studies (see Sabra, 2017; Genesee \& Lindholm-Leary (2013) and Linares \& Whittaker (2009). The present study attempts to use CLIL approach in English for Art course with Multicultural Art content.

Multiculturalism, as a course design approach, is one of world education policies. For instance, Europe has stressed multiculturalism in its documents and policies as CEFR, EPOSTL, and others (Seong, 2005). Multiculturalism as an approach is described by Carolan (2000, P. 2) to mean the following:

Multicultural perspectives in Art pertain to an educational approach that celebrates the multiple heritages of artists and students of art. No individual group is seen as dominant or superior. All aspects of cultural diversity are acknowledged in multiculturalism.

This approach proposes world experience to the learner during his/her learning of English. Thus, it paves the way to a whole process of acculturation. Since the language cannot be taught in 
isolation from culture. Multiculturalism proposes a variety of world cultures and in this prospect fosters learning. In this research, the different artistic works utilized represent various cultures and Art schools.

Based on the above approach in foreign language pedagogy, art, CLIL and Multiculturalism, this paper highlights theory and practices of using Art in the teaching of English as a foreign language from the multiculturalism perspective. To achieve this aim, the research implements a CLIL based Art module to develop participants' English language achievement as well as art-related content. The following review explores the variables of the research.

\section{Theoretical framework:}

This review aims at discussing Content and Language Integrated CLIL approach, Multiculturalism and its relation with Art, and finally the key studies that utilized Art as a means for language development. The review provides a framework to locate Art-related English courses for a better content and language practice.

It is not the role of the language educator to go into a deep analysis of Art or what it is; it is rather pointing out how Art is used as a means of language instruction. By placing Art within language classroom setting and enabling (Hashemi \& Farokhi: 2012) students to express their ideas visually as well as by speaking and writing, teachers can build on prior knowledge and scaffold instruction, enrich self-esteem and creativity as well as develop their thinking skills. These roles were identified By March (2001) to include language communication, theory and methodology, language learning environment, materials development, and assessment. He further states (ibid, p. 33) that "Generally speaking, CLIL teachers need to be simultaneously both language and content teachers. The emphasis may be more towards one of these than the other, depending on the teacher competences but nonetheless "dualinterest and dual-ability, if not dual qualification, appear to be highly desirable". In this view, the roles of language teachers have changed to a more integrated and content-diverse profession.

To integrate Art in language teaching, Witherell (2000, p. 5) suggests five basic principles of teaching through the arts that should be understood before the planning of effective Art integrated lessons. (1) Targeted outcomes must be clear since they cannot change because the teaching or assessment is nontraditional. (2) All possible arts (and 
intelligences) must be included, as long as this inclusion does not seem contrived. (3) Learning must be accomplished through the arts, supported by teaching through the arts. (4) All intelligences should be fostered while students continue to use reading, writing, and math skills in conjunction with the arts. (5) Assessment must fit the mode of presentation. These principles are the core of the multiculturalism approach to teach art.

Multiculturalism is an approach that also calls for integrating Art in English language classes. This approach resulted to this shift from English to world "Englishes". It is as an approach and multicultural education has been subject to criticism and misconceptions. The key misconceptions about multiculturalism and Art education (Delacruz: 2015) are the following:

1. Multiculturalism is for the "others".

2. Multicultural education is against the west.

3. Multicultural education will divide the nation.

4. Multiculturalism will pass; we will wait this one out.

5. Multicultural Art education means teaching about the Art everywhere.

6. Multicultural Art education is not about art.

World education has long called for the approach and highlighted its virtues (see Newby \& Penz, 2009); it has been considered as a requirement in an emerging world of cultures. It was called for as a means to be involved in a process of acculturation. In different perspective, Davis \& Waghid (2013, p. 4) claim that the problem besetting multiculturalism is its deficiency in recognizing the diversity of, and within, diversity itself -meaning that even within the recognition of difference there ought to be the recognition of difference within difference. Art is a teaching aid and it needs to be taught as a set content as well. Mueller (2015, p. 4) stresses that "It is naive of teachers to believe that visuals, such as paintings or photographs, are self-explanatory-that they need not be taught". In this perspective, language teachers should not only use Art as a teaching tool but need to implement Art values and Art "ingredient" in their students to understand and use it in their learning.

Example activities for using arts in language teaching were early suggested by Criscuolo (1985) included: costume sketches, famous faces, vacation souvenirs, matching shapes, pleasure scenes, tongue twisters, book review collage, personality puppets, scrambled sentences, cloudy issues, poetry cards, travel quilts, book motivators, book snails and shadow panels. 
An example: Matching shapes: (ibid: 3 )

In one column, teachers use squares of colors - red, yellow and blue - to correspond to a column of color words (in random order) beside it. Teachers have the child draw a line from the color square to the printed word. The child draws a line from the word shape to the corresponding word.

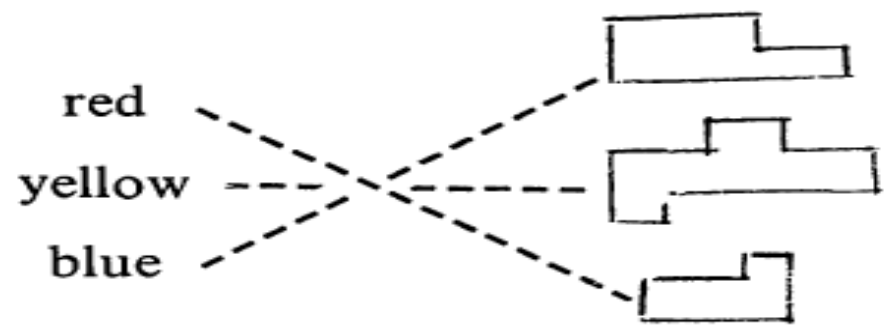

Figure (1) Matching example

Other Art related vocabulary can be used in the same way by this artlanguage integration. As an Art activity, just the configurations can be used by having children imagine what each configuration reminds them of and make a picture or design from them. When designing Art related activities (Haggag, 2013), active learning strategies should be implemented since they guarantee active participation from the learners and enhance their self-learning control.

To conclude, multiculturalism as an approach to integrate Art in English language teaching and learning can add effective practices for using the language communicatively. Integrating Art in language classes can add to both the linguistic diversity of the students and to their knowledge, skills and attitudes towards both language and art.

\section{Content and language Integrated Learning CLIL approach}

This approach to language instruction and course design implies the use of foreign language as a medium of instruction to instruct and learn both content and language at the same time. It was first defined by March (2006, p.3) as "CLIL is an approach in which a foreign language is used as a tool in the learning of a non-language subject in which both language and the subject have a joint role". CLIL courses are used for dual-focused aims; the learning of the content and the learning of a foreign language. Therefore, in this research, participants are asked to study the CLIL-based Art module for two aims; the first is learning 
English as a Foreign Language (EFL), then to study Art related content.

Designing an art-based module or a program stems from the nature of this umbrella term which differs from traditional content based courses. In this view, Garcia (2008, p. 264) states that "CLIL is an umbrella term that embraces any type of program where an additional language is used to teach non-linguistic content matter....it is always accompanied by explicit language instruction". CLIL is more dominant than other Content based Instruction CBI approaches especially in the European contexts. For instance, Wolf (2007, pp.15-16) stresses that "classroom content is not so much taken from everyday life or the general content of the target language culture but rather from content subjects, academic/ scientific or from the professions". Therefore, designing an Art module based on CLIL is actually compiling both an art-based content and a language course as well.

The link between CLIL approach and Multi Culturality in this research stems from the nature of CLIL 4Cs proposed by Coyle et al. (2010, p. 41). CLIL $4 \mathrm{Cs}$ includes culture, content, communication and cognition; they are interrelated as the following figure shows.

Figure (2): Coyle et al. (2010, p.41) CLIL Four Cs.

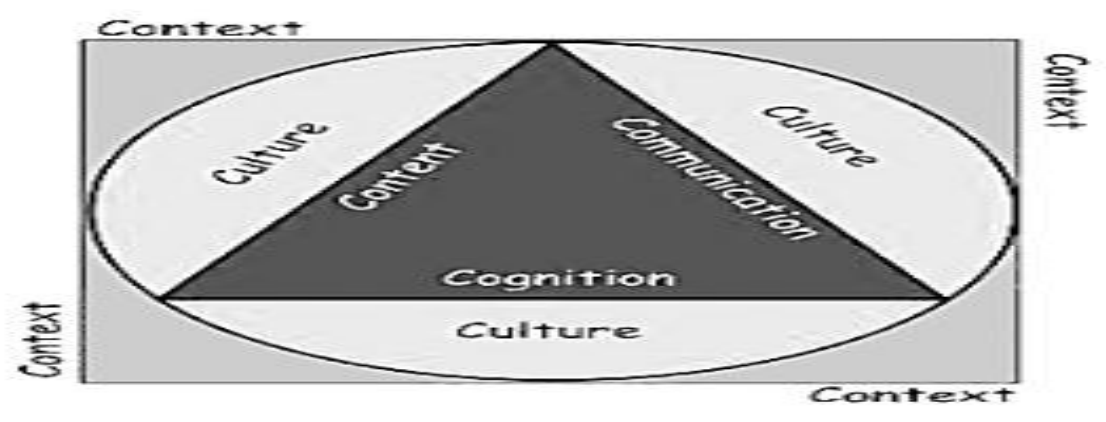

The above figure (2) shows how the four Cs highlight the value of CLIL in both instruction and course design. Coyle et al. (p.9) express the view that "the $4 \mathrm{Cs}$ framework suggests that it is through profession in knowledge, skills and understanding of the Content, engagement in associated cognitive processing, interaction in the communicative context... acquiring a deepening intercultural awareness through the positioning of self and otherness, that effective CLIL takes place". Therefore, CLIL approach promotes the multi-culturalism and 
therefore can link it together in content and language combination as the present research suggests.

Benefits of CLIL have been stressed by many researches and studies (see March, 2000; Lasagabaster, 2008; Munoz, 2002 \& TokuhamaEspinosa, 2008). For instance, Dalton-Puffer (2007, p. 3) view CLIL as a means for effective language communication stating that:

CLIL is the ultimate dream of Communicative Language Teaching CLT and Task Based Learning TBL rolled into one: there is no need to design individual tasks in order to foster goal-directed linguistic activity with a focus on meaning above from, since CLIL itself is one huge task which ensures the use of the foreign language for authentic communication.

Thus, CLIL and communication are coined and this urges the present research to utilize it in a multi-cultural perspective to achieve both content and language based learning outcomes. In this view, March et al. (2001) integrate five dimensions to be added to CLIL (culture, environment, content, language and learning). The following figure shows how these dimensions are interrelated and coined together.

Figure (3) CLIL Dimensions (Ibid, p. 31)

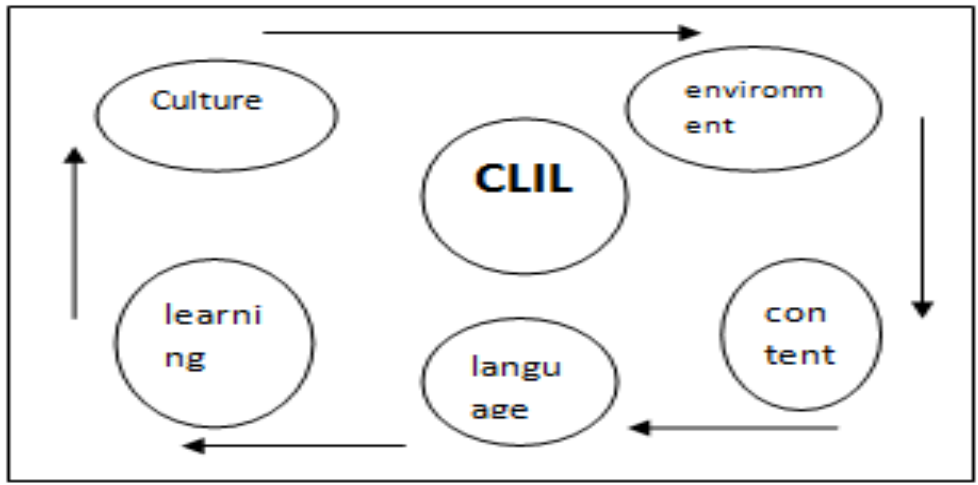

The above tigure (3) shows that culture as well as learning, language, content and environment form the various dimensions of culture. Culture plays a key role in understanding the wider culture-related contexts. According to Byram (2008, p. 54), "studying trough "different languages is fundamental to fostering international understanding. If learners understand the concept of otherness, this is likely leads to understanding self". Combining culture to CLIL can be supported by literature related to foreign language development (see Sousa, 2001 and March, 2001). 
Similarly, Thornbury (2006, p. 51) stresses the value of CLIL approach in achieving both language development and Art achievement:

"Content and language integrated learning instruction probably works best where teachers are adept not only at teaching the subject matter, but also at addressing their learners' language needs, such as being able to modify their own classroom language, and to provide 'in flight' assistance when necessary".

To sum, designing an art-related English course using CLIL approach may lead to positive development in both content achievement and language development.

To conclude, CLIL has a dual aim that can be expressed in promoting both knowledge of the content as well as language skills development. It embraces both content of the course as well the aspired language skills. In the light of this review, the following objectives are defined.

\section{Objectives of the research}

The research seeks to achieve the following:

1. Designing a CLIL based multi-cultural Art Module.

2. Identifying the effect of the Module on participants' English language achievement.

3. Identifying the effect of the designed CLIL Art Module on participants' satisfaction.

\section{Hypotheses of the research}

1. There are statistically significant differences between the mean scores of the participants in the pre- post testing of English language achievement favoring the post testing.

2. There are statistically significant differences between the mean scores of the participants in the pre- post testing of their satisfaction favoring the post testing.

\section{Questions of the research:}

1. What is the effect of the CLIL based module on participants' language achievement?

2. What is the effect of the CLIL based module on participants' satisfaction towards it?

\section{Methodology \& Design:}

The research follows the one group quasi-experimental design with its pre and post testing procedures. Participants of the research were (25) English language post graduates doing their special diploma at 
Hurghada Faculty of Education. A number of (255) participated in the questionnaire and the needs assessment tool (refer to instruments part) in both online and traditional forms. Delimitations of the research included four language areas to be included in the module (vocabulary, grammar, reading and writing). The delimitations also included the participants who had prior knowledge with teaching (a minimum of 2 years). It was also delimited to the artistic paints and famous works included in the module (refer to appendix).

\section{Design}

Using the quasi-experimental one-group design, 25 participants were selected and adjusted according to specialization and teaching experience. Participants were informed with the training and assessment plan (that included formative and summative assessments) and the type of quizzes and tests they have to be trained on. An Artrelated module that is based on CLIL multicultural approaches was administered to achieve the two main goals of the research. Using the pre and post testing of English language achievement and satisfaction, results were reported using SPSS statistical program.

\section{Instrumentation:}

The research utilized the following (6) instruments that were designed and administered by the researcher: (1) Content Analysis Questionnaire (2) Needs Assessment Questionnaire (3) CLIL Artoriented questionnaire (4) CLIL Art-oriented Module (5) CLIL Test (6) Satisfaction scale. The instruments were updated with QR codes for easier Mobile use by the participants.

A. A content analysis questionnaire that aims at identifying the content of English language courses for Art. This questionnaire provided a framework for integrating Art in course design teaching English for Art courses. It highlighted the theory and possible practice of integrating Art with English from participants' viewpoints.

B. Needs assessment questionnaire that aims at identifying teachers' views about the teaching of English for Art and means of using Art in their teaching practices.

C. CLIL Art-oriented language skills questionnaire that aims at collecting data and evidence about the best practices of designing Art related activities in the teaching of English as a foreign language. It also aims at identifying the content and language areas to be utilized in the course. 
D. CLIL Art oriented module that aims at developing students' achievement in the English language using Art related content. It covers four main areas (grammar, vocabulary, reading and writing). The module includes integrated activities that integrate the four areas of the module in an Art oriented texts and resources.

E. CLIL test that aims at measuring students' English language achievement. The test covers four sections (Vocabularygrammar- reading - writing).

F. Satisfaction scale that aims at identifying students' satisfaction with the English course.

Total number of the participants in the three questionnaires were $(N$. 255); a number of (100) participated in the first questionnaire, (120) in the second and (35) in the third questionnaire. They had to complete the three questionnaires in print or online (URL: https://www.surveyanalytics.com/a /Survey). Following is an analysis for the key results of the questionnaires. The randomly selected participants in the research were (25); they were trained on the module and responded to the tests. The instruments were adjusted using content validity - jury validation- and test-retest reliability (test reliability was $(0.79)$ while the satisfaction scale reliability was $(0.88)$. As to jury validation, comments of the jury included instructions' clarification, items modification and language areas relevance. The jury agreed that the areas that should be covered in the test are (Grammar, Vocabulary, Reading and Writing); other language skills were deleted from the first form of the test. The sample chosen for adjustment of the test were (10) participants from the special diploma too. The final selected participants in the course were (25) participants doing their special diploma at Hurghada Faculty of Education, South Valley University and they have a prior experience with teaching.

\section{Results:}

Using SPSS program, validity and reliability of the questionnaires were calculated. Items of the questionnaires were divided into odd and even ones and then using Split-Half statistical calculation, reliability was firstly calculated and then the Square Root of the obtained mark indicated validity. The obtained reliability degrees were $(0.21$ for the needs assessment questionnaire, $(0.11)$ for the teacher questionnaire and (0. 34) for the activities questionnaire) respectively. The pre- post testing of achievement test showed significant means differences 
between the two tests favoring the post test (sig. 0.001), which is a high significance. The same significance was obtained in the pre and post administration of the satisfaction scale favoring the post administration.

The qualitative obtained data from the first two tools (needs analysis and content analysis) are visualized in the following two figures. The following figures represent the results of the closed answer section. Figure (4) shows the views of the teachers (N.100) while figure (5) shows their views about the content presented in language courses that utilize Art as a means of instruction. Figure (4) shows the obtained results from the first closed-answer question "do you use Art in your class teaching?" and it indicates that only (28\%) of the participants use Art in their teaching. Responses to item (2) "Do you think Art is a key component in language courses?" showed that (14\%) of them agree on the item. The figure also represents results obtained from item (3) responses "Do you think Art can be effectively used in teaching new language?" It shows that $(29 \%)$ of the participants agree on the item. The last percent (29\%) goes for item (4) "do you think Art use suits various English language levels and courses?" as the following figures indicate.

Figure (4)

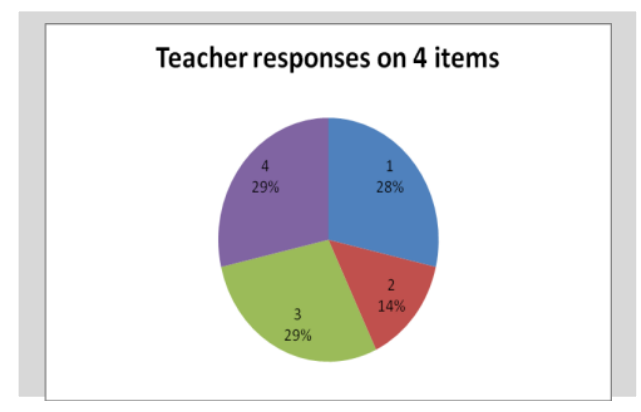

Reponses to Needs Assessment Questionnaire
Figure (5)

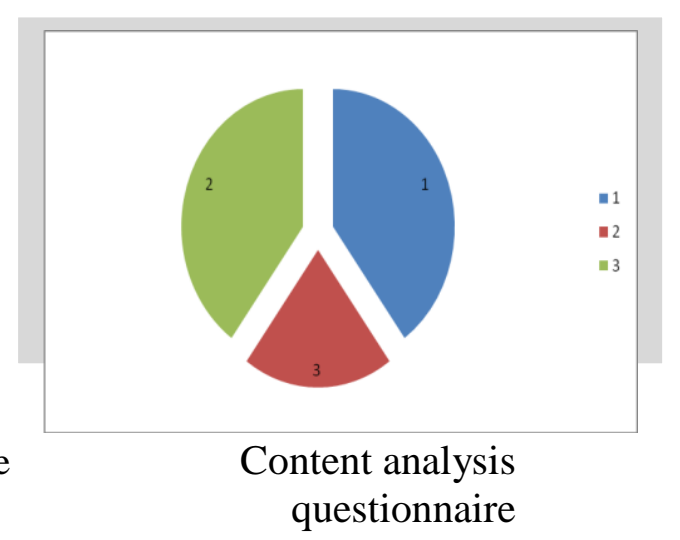


Results obtained from analyzing the content analysis instrument is visualized in figure (5). Responses of the participants regarding the content (N.120) are grouped into three parts: the first is about their knowledge with the content and Art in learning English. The second is about their skills in using Art content in learning English contents. The third is about identifying their attitudes towards using Art content in learning English. The obtained results showed the following percent regarding the analysis of the questionnaire contents $(20 \%, 40 \%$ and $40 \%)$ respectively. This means that analyzing participants' knowledge about the content showed the lack in their knowledge with the artrelated courses. Similarly, they face problems with both the skills and attitude towards Art-related courses or CLIL courses.

The obtained results from the Art-oriented questionnaire covered two main sections (Theory about TEFL and art) and (Practice about TEFL and Art). Results showed that (67\%) of the participants have prior knowledge with the first section (Theory) and (33\%) of them performed less on the second section (practice). This result shows that although participants were aware of the value of Art in education and language but could not state clearly how to integrate it in the actual teaching practices. Final results suggested four areas to be included in the module of the research (Vocabulary, grammar, reading and writing). The results assure what Siegesmund (2014) claims about the aim behind English for Art teaching, which is language skills development as well as content achievement. Similarly, the above results agrees with Grauer's (2014) and Sabra (2017) stressing the importance of content integration with language for better knowledge, skills and attitudes.

\section{CLIL test results:}

To verify the effect of the proposed module, the following statistical analysis was run; the following table shows the differences in participants' means.

Table (1) : CLIL teat results for Means differences

Paired Samples Statistics

\begin{tabular}{|ll|r|r|r|c|}
\hline & Mean & $\mathrm{N}$ & Std. Dev iation & $\begin{array}{c}\text { Std. Error } \\
\text { Mean }\end{array}$ \\
\hline Pair 1 & preachieve & 50.72 & 25 & 7.272 & 1.454 \\
& postachi & 72.56 & 25 & 6.364 & 1.273 \\
\hline
\end{tabular}


The above table shows the difference in means of the participants over the two tests (pre 50.72) and (post 72.56). This difference favors the post testing since its mean is greater than the pre- testing. To verify if the following difference is significant or not, the following analysis was run.

Table (2) CLIL test results and significance

Paired Samples Test

\begin{tabular}{|c|c|c|c|c|c|c|c|c|}
\hline & \multicolumn{5}{|c|}{ Paired Differences } & \multirow[b]{3}{*}{$\uparrow$} & \multirow[b]{3}{*}{$d^{d f}$} & \multirow[b]{3}{*}{ Sig. (2-atilec } \\
\hline & \multirow[b]{2}{*}{ Mean } & \multirow[b]{2}{*}{ Std. Deviation } & \multirow{2}{*}{$\begin{array}{l}\text { Stald Error } \\
\text { Mean }\end{array}$} & \multicolumn{2}{|c|}{$\begin{array}{l}95 \% \text { Confidence } \\
\text { Interval of the } \\
\text { Difference }\end{array}$} & & & \\
\hline & & & & Lower" & Upper" & & & \\
\hline Pair 1 preachieve - postachi & .21 .840 & 9.982 & 1.996 & .25 .960 & .17 .720 & .10 .940 & 24 & .000 \\
\hline
\end{tabular}

The above table shows that there are statistically significant means differences between participants' scores in the pre and post tests favoring the post test (sig. 001). This proves the alternative hypothesis and rejects the null hypothesis and proves that the CLIL Art oriented module could develop English language achievement of the participants. To verify which section of the test (Grammar-Vocabulary-ReadingWriting) reported the highest scores and therefore participants have performed better, the following analysis was run: 


\section{Table (3): Test sections' results}

Paired Samples Statistics

\begin{tabular}{|c|c|c|c|c|c|}
\hline & & Mean & $\mathrm{N}$ & Std. Deviation & $\begin{array}{l}\text { Std. Error } \\
\text { Mean }\end{array}$ \\
\hline \multirow[t]{2}{*}{ Pair 1} & pregr & 11.12 & 25 & 3.420 & .684 \\
\hline & postg & 16.68 & 25 & 3.262 & .652 \\
\hline \multirow[t]{2}{*}{ Pair 2} & prevoc & 11.24 & 25 & 3.018 & .604 \\
\hline & postvoc & 17.80 & 25 & 3.582 & .716 \\
\hline \multirow[t]{2}{*}{ Pair 3} & preread & 11.12 & 25 & 3.127 & .625 \\
\hline & postread & 19.28 & 25 & 2.372 & .474 \\
\hline \multirow[t]{2}{*}{ Pair 4} & prewri & 17.24 & 25 & 3.700 & .740 \\
\hline & postwrit & 18.80 & 25 & 3.416 & .683 \\
\hline
\end{tabular}

The above table shows that means of the participants were better in the post testing. The scores reported at the four sections were (19.28) in reading, (18.70) in writing, (17.80) in vocabulary then (11.68) in grammar. The following table shows the significance of these means differences over the participants.

\section{Table (4) : Significance of test sections}

\begin{tabular}{|c|c|c|c|c|c|c|c|c|}
\hline \multicolumn{9}{|c|}{ Paired Samples Test } \\
\hline & \multicolumn{5}{|c|}{ Paired Differences } & \multirow[b]{3}{*}{$\mathrm{t}$} & \multirow[b]{3}{*}{$d f$} & \multirow[b]{3}{*}{ Sig. (2-tailed) } \\
\hline & \multirow[b]{2}{*}{ Mean } & \multirow[b]{2}{*}{ Std. Deviation } & \multirow{2}{*}{$\begin{array}{l}\text { Std. Error } \\
\text { Mean }\end{array}$} & \multicolumn{2}{|c|}{$\begin{array}{l}95 \% \text { Confi dence } \\
\text { Interv al of the } \\
\text { Difference }\end{array}$} & & & \\
\hline & & & & Lower & Upper & & & \\
\hline Pair 1 pregr - postg & -5.560 & 5.561 & 1.112 & -7.855 & -3.265 & -4.999 & 24 & .000 \\
\hline Pair 2 prevoc-postvoc & -6.560 & 5.075 & 1.015 & -8.655 & -4.465 & -6.463 & 24 & .000 \\
\hline Pair 3 preread - postread & -8.160 & 3.105 & .621 & -9.442 & -6.878 & -13.141 & 24 & .000 \\
\hline Pair 4 prewi-postwit & -1.560 & 5.501 & 1.100 & -3.831 & .711 & -1.418 & 24 & .169 \\
\hline
\end{tabular}

The above table (4) shows that there are statistically significant means differences in the four sections of the test favoring the post testing. The greatest difference was in the reading section followed by the writing section, then vocabulary and finally grammar. This result answered the first question in the research.

\section{Results obtained from Satisfaction Scale:}


A statistical analysis was run to identify students' satisfaction with the CLIL module. Using T-test analysis the following results were obtained.

Table (5) : Sample statistics for Satisfaction scale

\begin{tabular}{|rr|r|r|r|c|}
\hline & & & \multicolumn{1}{|c|}{$\begin{array}{c}\text { Std. } \\
\text { Deviation }\end{array}$} & $\begin{array}{c}\text { Std. } \\
\text { Error } \\
\text { Mean }\end{array}$ \\
\hline Pair & pre & 55.20 & 25 & 6.538 & 1.308 \\
1 & post & 60.04 & 25 & 7.580 & 1.516 \\
\hline
\end{tabular}

The above table shows the differences in participants' means over the scale in the pretest (55.20) and posttest (60.04). The results show a greater means difference favoring the post testing. To verify the difference, the following statistics were run as the table shows.

\section{Table (6) Comparing means}

Paired Samples Test

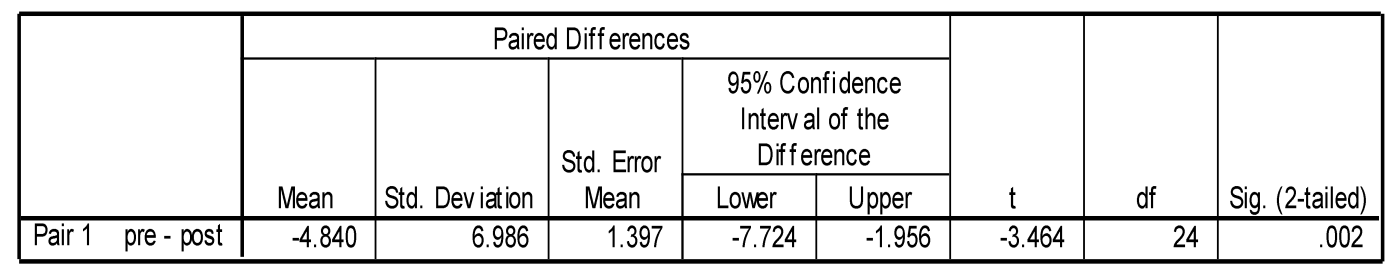

The above table shows that there are statistically significant means differences between participants' scores in the pre and post tests favoring the post test (sig. 002). This means that the participants were satisfied with the CLIL course and felt it is useful for them. This result answered the second question in the research.

To conclude, the results obtained from the content analysis questionnaire showed that the majority of the participants (67\%) stressed the value of using Art in their classes although they do not actually use it (only 33\%). This can be due to tight time frame, current courses or lack of training. As to needs assessment questionnaire, it reveals that participants' skills and attitudes are better than their knowledge about the impact of Art in their learning to English. This can be due to their academic programs or lack of interdisciplinary courses. The teachers' questionnaire reveals their positive attitude towards the value to using Art in teaching from the one hand and their inability to integrate it in their teaching practices due to lack of training or their academic preparation. Analyzing the scores of the participants in the pre post tests of CLIL test reveals that there are statistically significant 
means differences in their score favoring the post testing (sig. 001). This shows the impact of the program in developing the grammar, vocabulary, reading and writing (test sections) of the participants. Analyzing the satisfaction scale shows that the participants were satisfied with the course as the results showed (sig. 002). These results emphasize the use of Art in teaching English as a foreign language using CLIL based programs.

\section{Discussion}

Two main findings were obtained from the research: (1) The CLIL Art oriented module could develop participants' language achievement. (2) The module could enhance participants' satisfaction with the Art course (sig 0.001). These results highlight the value of CLIL courses and modules, a result which agrees with other studies as Lasagabaster (2008) and Zarobe (2008); both the studies promote the use of CLIL in learning both the content and language as well. The obtained results promote the value of using CLIL in language courses as Dalton-Puffer (2007, p. 3) stresses this value stating that "CLIL is ultimate dream of communicative language teaching and task based learning rolled into one. There is no need to design individual tasks in order to foster goaloriented linguistic activity with a focus on meaning above form".

The value of Art in English language development - as obtained from the results- promote the need for interdisciplinary course design approaches. This interdisciplinary approach in course design integrated between various disciplines for better language development. Rooney (2004, p. 19) expressed the view that "'Cross-disciplinary professional development helps diverse instructors learn a common language and strategies for learning, and explore the possibilities of co-teaching. Cross-disciplinary professional development models bring teachers, arts instructors and artists together to address common strategies". Integrating various disciplines in teaching the language enriches the teaching practices and promotes students' thinking and critical skills.

The results highlight the value of professional art-based teaching strategies to achieve the aim behind CLIL or interdisciplinary courses. Eisner (2002) expressed the view that Art-based instruction van help teachers to promote diversity and individuality. In his study about Art and storytelling integration, two groups of students were compared; a one that utilized art-based activities and another that "struggles with academics". Results showed that the group that utilized Art in class 
discussion and learning performed better in storytelling. Therefore, there is a need to train teacher on how to deal with art-related English courses.

Learners' satisfaction was examined by Grave Rousseau (2011) who stressed real like activities as a means to develop language satisfaction and motivation. The same results was stressed by March (2000, p. 10) who stated that "A major outcome of CLIL is to establish not only competence in two languages, but also nurture a "can do" attitude towards language learning in general. So very often CLIL language will itself only be a platform by which the youngster may ultimately take an interest in other languages and cultures as well". March stressed the "feel good attitude" obtained from studying CLIL courses. This satisfaction that leads to a positive attitude is not only for learning but also for the course itself.

Since the learners may have a positive attitude towards learning but not to a course or vice versa, CLIL, in the light of the results, promotes satisfaction with the course and to learning itself. Similarly, this positive satisfaction was stressed by Coyle $(2009$, p.25) stressing the view that "the classroom environment, the extent to which learners are willing to engage in learning which is constructed in and grown from that environment along with the impact this has on the learner's own sense of self as a learner and competent language user, are all significant contributors to learner motivation". The online classroom included positive comments from the participants that indicate their satisfaction with the module. For instance Abeer Matkk commented "I couldn't imagine I can learn English from my description to a picture by Picasso". Similarly, Doaa Mahmud commented "the activities are very attractive to me and I feel I can talk about Art in English very well now". These comments -as well others- reveal how the participants were satisfied with course next to the obtained results from the questionnaire.

A key obtained result from the achievement test is participants' general language development at the four sections of the test. Their mean scores were (19.28) in the reading section, (18.70) in writing, (17.80) in vocabulary and in grammar was (11.68). The highest score was attributed to the reading section. This result was supported by Sabra (2017) who reported the use of CLIL in developing reading skills related to a different field which was history. This result indicates that CLIL can lead to positive developments in the reading skill more than other language skills and this can be attributed to the type of texts 
related to the core content of the courses. Participants tend to read and understand what they "want" to read and "feel" it is crucial for their academic achievement.

To sum, implementing CLIL Art oriented modules can lead to positive developments in both language achievement and positive satisfaction towards English language and Art courses.

\section{Implications of the research:}

In the light of the obtained results, the following implications and "to do" ideas can be generated regarding the use of Art in English language teaching:

1. Designing CLIL based programs that develop other specialized language fields or English for Specific Purposes areas such as (e.g. Sculpturing and Drawing).

2. Highlighting Art as a key element in the knowledge, skills and attitudes towards English language teaching and learning. Thus, it should be integrated in the language courses of all the stages and levels.

3. Preparing and training English language teachers should include how to value and use Art in their teaching practices. In this view, practicum at the faculties of education should highlight this and discuss it with mentors and supervisors.

4. Supplementing new methods of integrating Art in the online and offline courses and modules should be provided and trained in the pre-service and in-service levels.

5. Integrating Art related language courses should include Art related reading passages that both develop the content and the language as well.

\section{Recommendations of the research:}

In the light of the obtained results, the research recommends the following:

1. Teaching teachers how to integrate Art in their language classes. This can be done through a professional development workshop, training or seminars.

2. Adding art-related activities in the daily class activities or as part of class routine.

3. In assessment, adding art-related questions as part of tests and exams that function as "context" for language areas. The aim of these questions is to assess language in the first place rather than knowledge of Art. 
4. Designing other CLIL based modules that integrate language, culture and content to foreign language learners; these courses can be in traditional or online formats.

5. Supporting co-teaching and interdisciplinary courses that integrated and accumulate between language and Art teachers.

\section{Conclusion:}

Art is a key discipline that can be integrated in the teaching of English as a foreign language. It fosters (refers to whom?) autonomous learning and their multicultural understanding. This research discussed the results obtained from 3 questionnaires, a test and a scale about the English language courses and their integration to Art courses. Based on the qualitative and quantitative obtained results, Art-oriented activities should be used and highlighted in English classes. Courses should include Art as an important discipline on the one hand and training should carry out this art-based approach during the processes of courses design on the other. Results also highlighted the significance of CLIL Art-oriented courses in developing both language and content. The research calls for co-teaching and interdisciplinary curriculum which integrates between various disciplines such as adding Art discipline to English to achieve a collective aim. There were some barriers that encountered the research such as time frame constraints, participants' lack of Art knowledge and changing module format into an online digital form. Using an online virtual classroom "via Google Classroom" as well as class discussions could solve these challenges and achieve the objectives of the research. 


\section{References}

1. Asagabaster, D. (2008). Foreign language competence in content and language integrated courses. Journal of the Open Applied Linguistics, 1(1), 31-41

2. Byram, M. (2008). From Foreign Language Education to Education for Intercultural Citizenship: Essays and Reflections.

Clevedon: Multilingual Matters.

3. Carolan, J. ( 2000). Pluralism in Art definition. Retrieved: http://www.design.iastate.edu/

NAB/about/thinkingskills/cultural_context/pluralism.html. Last visit $\{16.1 .2015\}$

4. Colyle, D. (2009). Promoting cultural diversity through intercultural understanding: a case study of CLIL pedagogies. International Journal of Bilingual Education and Bilingualism, 10 (5), 543-652

5. Colye, D., Hood, P., \& Marsh, D. (2010). CLIL: Content and language integrated learning. Cambridge, UK: Cambridge University press.

6. Criscuolo, P. (1985). Creative approaches to teaching reading through art. Art Education, 38(6), 13-16.

7. Dalton-Puffer, C. (2011). Content - and- language integrated learning: from practice to principles? Annual Review of Applied linguistics, 31, 182-204

8. Delacruz, E. (2014). Multiculturalism and Art education: Myths, misconceptions, and misdirection. Journal of National Art Education Association.

Retrieved: www.jstore.org/stable/3193523. Last visit $\{14.04 .2017\}$

9. Eisner, W. (2002). The arts and the creation of mind. New Haven: Yale University Press.

10. Garcia, O. (2008). Bilingual Education in the 21st Century.

Hoboken, $\mathrm{Nj}$ : Wiley-Blackwell.

11.Genesee, F., \& Lindholm-Leary, K. (2013). Two case studies of content-based language education, 1, 3-33. Doi:10.1075/jicb.1.1.02 gen, Last visit $\{14.04 .2017\}$

12. Grauer, K. (2014). Beliefs of pre service teachers toward Art education. National Art education association. Vol 39 (N.4), $350-370$

13.Grave Rousseau, R. (2011). Language yesterday and today from the perspective of the foreign language. Retrieved : 
http://www.emilangues.education.fr/international/emile. Last visit $\{12-03-2017\}$

14.Hashemi, M. \& Farokhi, M. (2012). The impact/s of using Art in English language learning classes. Journal of Social and Behavioral Sciences, 31, 923 - 926

15.Linares, A. \& Whittaker, R. (2006). Oral and written production in social science. Current Research on CLIL. Views Journal, 15 (3), 28-32

16. Marsh, D. (2002). CLIL/EMILE - The European Dimension: Actions, Trends \& Foresight Potential. Brussels: European Commission

17.Marsh, D. (2000): Profiling European CLIL Classrooms: European Commission Handbook). European Commission, Council of Europe Prints, Brussels

18.Mueller, L. (2015). Language as Art and Art as language. The English Journal, 66, (7), 49-53

19.Muñoz, C. (2002). Relevance \& potential of CLIL, in D. Marsh (ed.),CLIL/EMILE. The European Dimension. Actions, Trends and Foreight Potential. Strasbourg: European Commission.

20.Newby, D. \& Penz, H. (2009). Languages for social cohesion: Language education in a multilingual and multicultural Europe. ECM, Council Of Europe, Graz, Austria

21.Rooney, R. (2004). Art-Based Teaching and Learning, Review of the Literature. The Kennedy Center, NW Washington DC, USA

22.Sabra, I. (2017). A proposed program based on Content and Language Integrate d Learning CLIL approach to develop some History section students' language skills. MA Thesis, South Valley University

23.Seong, S. (2005). Multicultural Education in Europe and its implications for Korea. Retrieved : http://www.welt.de/welt_print/article1423373/Deutschland_brau ch. Last visit $\{16.02 .2017\}$

24.Siegesmund, R. (2014). Why do we teach Art today? National Art Education Association. Vol. 39 (N. 3)

25.Sousa, D. (2006). How the Brain Learns. California: Corwin Press Sage

26.The NY state department office, (2010). Art as a tool for teachers of English language learners. The university of the State of N Y, Albany, NY 12234

27. Thornbury, S. (2006). An A-Z of ELT. . Macmillan, Oxford, 2006. 
28.Tokuhama-Espinosa, T. (2008) Living Languages: Multilingualism Across the Lifespan. Westport, CT: Praeger Publishers.

29.Vazques, D. (2014). Teaching a second language through art. Retrieved:

http://www.yale.edu/ynhti/curriculum/units/1981/4/81.04.12.x.ht ml. Last visit $\{11.04 .2017\}$

30.Waghid, Y., \& Davids, N. (2014). Muslim Education and its (In) commensurability with Multiculturalism: some thoughts on the imaginative school. Policy Futures in Education, 12(1), 124-130.

31.Wales. R.J. \& Marshall. J.C. 1966 In Lyons and R. Wales (ed.). Psycholinguistics Papers. The proceedings of the Edinburgh conference. Edinburgh university press.

32.Witherell, N. (2000). Promoting understanding: Teaching literacy through the arts. Educational Horizons, 78(4), 179-183.

33.Wolf, D. (2009). Content and Language Integrated learning CLIL. In Knapp, K. F. \& Seidelhofer, B. in cooperation with Henry Widdowson (eds.). Handbook of Foreign Language Communication and Learning 5 (21), 545-572. Berlin : Mouton de Gruyter

34.Zarobe, Y. (2008). CLIL and foreign language learning. Retrieved : http://www.icrj.eu/11/article5.html, Last visit \{16-4-2017\} 
